\title{
PSICOLOGIA CONCRETA E HUMANISMO: FOUCAULT CRÍTICO DE POLITZER?
}

\author{
Carolina de Souza Noto
}

Resumo: No presente artigo pretendo confrontar a crítica que Foucault faz à psicologia e à psicanálise em seus textos da década de 1950, com aquela que Georges Politzer desenvolve em seu famoso Crítica dos fundamentos da psicologia, de 1928. Trata-se de mostrar que apesar de alguns pontos de convergência, a crítica de Foucault é, desde o início, mais radical que a de Politzer e atinge a própria psicologia concreta proposta por este.

Palavras-chave: psicologia - psicanálise - crítica - Foucault - Politzer

No livro de 1928, Critique des fondements de la psychologie, Georges Politzer, pensador de origem húngara e radicado na França desde 1921, estabelece algumas considerações acerca da psicologia. Tais considerações serão determinantes para uma longa tradição da filosofia francesa posterior que irá se interessar pela relação entre filosofia e psicologia e em especial pela relação entre filosofia e psicanálise.

O livro é publicado 2 anos depois da primeira tradução francesa de $A$ interpretação dos sonbos (Die Traumdeutung) de Freud e é principalmente com essa obra freudiana de 1900, que praticamente revoluciona o cenário teórico da psicologia, que Politzer dialoga.

Marxista convicto, Politzer via com maus olhos qualquer idealismo em filosofia; interessava-se mais pelos aspectos materiais da vida dos homens. Nesse sentido, suas análises no domínio da psicologia seguem à risca sua orientação no campo político. E se nesse último domínio pode-se dizer que é partidário de um materialismo dialético, no campo da psicologia Politzer inova com o termo "psicologia concreta" para se referir a um tipo de investigação que mais do que abstrações formais ou ideais está focado no aspecto concreto da vida de cada um de nós.

Não nos cabe aqui estabelecer os possíveis paralelos entre o materialismo histórico e a psicologia concreta de Politzer ou entre política e psicologia 2 . Interessa-me aqui retomar a crítica politzeriana à psicologia clássica a fim de verificarmos seu alcance filosófico mais profundo. Alcance filosófico mais profundo que, como veremos, aponta para certa maneira de pensar o homem: não tanto em termos daquilo que ele é, idealmente e universalmente, por essência natural,

\footnotetext{
1 Professora do Departamento de Filosofia da Universidade Federal de Santa Catarina. E-mail: carunoto@hotmail.com

2 Para uma visão geral sobre o assunto sugiro a apresentação de Giuseppe Bianco ao artigo "O fim da psicanálise”, de Politzer.
} 
mas como ele é, concreta e singularmente. É essa antropologia ou esse humanismo implícito no pensamento de Politzer que valem ser resgatados a fim de que seja possível estabelecermos um diálogo entre a psicologia concreta de Politzer e as críticas que, quase trinta anos depois, Foucault tecerá à psicologia como um todo e que, como veremos, respingará também na psicologia concreta do autor da Critique.

O presente artigo está dividido em duas partes. Na primeira, retomaremos o livro de Politzer e acompanharemos os argumentos do autor a favor de uma psicologia concreta, uma psicologia livre dos vícios da abstração da psicologia clássica e que nos dá subsídios para compreender o sentido psicológico singular das ações humanas. A segunda parte do artigo será dedicada a Foucault e aos seus primeiros textos sobre psicologia. Encontraremos neles uma crítica de Foucault não só à psicologia clássica do século XIX, mas também à psicanálise e ao existencialismo. Com isso, veremos que a crítica de Foucault à psicologia é mais radical do que aquela formulada por Politzer. Afinal, aos olhos de Foucault, nem mesmo uma psicanálise livre dos prejuízos clássicos da abstração e ocupada com o concreto estará livre de problemas. O primeiro deles diz respeito ao caráter restrito da empreitada: a psicologia concreta ou a psicanálise está presa ao sentido psicológico de nossas ações, não tem alcance ontológico e nada nos diz sobre os modos de ser e de existir do homem. Com os termos de Foucault: não passa de um humanismo ou antropologismo. Mas engana-se aquele que achar que a crítica foucaultiana à psicologia coroa-se com a defesa de uma inflexão da psicanálise ao existencialismo, nos moldes de Binswanger, ou mesmo de Sartre e de Merleau-Ponty. Como veremos, se, num primeiro momento, o alcance existencial e ontológico da psiquiatria existencial aparece como uma opção interessante para se superar o humanismo da psicanálise ou da psicologia concreta de Politzer, não demorou muito para Foucault problematizar também a perspectiva existencial. É o que se percebe já no primeiro livro de Foucault, publicado em 1954, Maladie mentale et personalité, onde o filósofo impõe a necessidade de se ultrapassar a psicologia, não só aquela do século XIX, mas sobretudo a psicanálise e a psicologia existencial, que restringiam suas análises às condições subjetivas do mental. Tratava-se, pois, de uma virada objetivista. Era preciso sair do sujeito. Coisa que Politzer, ao menos na Critique, não fez.

\section{I - A psicologia concreta de Politzer}

Como o próprio título do livro anuncia, a obra de Politzer consiste numa crítica da psicologia; não numa crítica qualquer, mas de seus fundamentos. Afinal, assegura Politzer, diversas críticas já foram endereçadas à psicologia, mas nenhuma delas fora radical o suficiente para abalar seus fundamentos; todas elas omitiram o essencial ${ }^{3}$. Nesse sentido, arremata o autor, era preciso fazer com a psicologia o mesmo que Kant fizera com a metafísica: rever a legitimidade daquilo que

3 Cf. POLITZER, Crítica dos fundamentos da psicologia, vol. I, p. 10 (a partir de agora a referência aos dois volumes desse livro será: Crítica I e Crítica II) 
se estabelece como seu fundamento, assim como propor uma nova maneira de pensar. Era preciso, enfim, promover uma revolução no interior da psicologia; ultrapassar a psicologia clássica, abstrata e formal, em favor de uma nova orientação, de uma nova psicologia orientada para o concreto 4 .

Ao falar em psicologia clássica, Politzer se refere de modo geral à psicologia experimental do século XIX e, em particular, à psicologia da introspecção de Wilhelm Wundt que, em 1873, publica Princípios de psicologia fisiológica (Grundzüge der Physiologischen Psychologie), e abre em 1879, na Universidade de Leipzig, o primeiro laboratório de psicologia experimental.

Como entender, em linhas gerais, essa psicologia?

Primeiramente, podemos dizer, que essa é uma psicologia que procura explicar o fato psicológico em termos físicos. Tenta encontrar para todo evento psíquico, um fato físico correspondente. Nesse sentido, é uma psicologia que dá papel central à fisiologia, em particular, à fisiologia das percepções; afinal, é o funcionamento de nosso organismo físico que determina o funcionamento de nosso aparato mental; as percepções são nosso primeiro contato com o mundo, nossa primeira fonte do mundo. Por isso a importância de explicar como funciona nosso aparato perceptivo: quantificar a intensidade dos estímulos que o tocam; calcular o tempo de resposta aos estímulos; formular as leis que regem esse funcionamento; descrever as ações envolvidas etc.

Ao que tudo indica, Wundt aprendeu bem a lição dos empiristas: todo conteúdo mental, ou todo conhecimento, deriva das sensações. Basta saber analisar, para retomar uma noção chave de Condillac. É precisamente o procedimento analítico que está por trás do método de introspecção de Wundt. Para explicar um fato psicológico é preciso, pois, saber analisar nossa experiência imediata; olhar com atenção o que se passa na consciência, separando e analisando o que é de ordem conceitual (representações simbólicas de amizade e de amor, por exemplo), quais são os sentimentos que acompanham os conceitos (se prazer ou desprazer, amor ou ódio) para, por fim, chegar àquilo que pode ser medido e calculado com mais precisão: as sensações e os movimentos corporais que acompanham e, no mais das vezes, ocasionam, as vivências internas, o conteúdo da consciência (como a sensação de frio e quente ou um movimento de palpitação).

Aos olhos de Politzer, entretanto, o problema não parece ser exatamente o empirismo; não há nada de problemático em considerar os sentidos, a percepção ou o corpo como fontes legítimas de conhecimento. O problema é reduzir a psicologia, uma ciência que deve nos ajudar a compreender a singularidade de cada um, a uma ciência do corpo. Em última instância a crítica de Politzer à psicologia clássica consiste em afirmar que essa não pode ser chamada propriamente de psicologia, pois é, antes de tudo, biologia ou ainda medicina.

Para Politzer, uma das condições para a psicologia tornar-se uma ciência é ela delimitar sua especificidade frente à medicina e demais ciências naturais. É isso, em primeiro lugar, o que a psicologia clássica enquanto psicofisiologia não fez; não tomou como objeto de análise aquilo que,

4 Politzer assevera ainda no Prefácio do primeiro volume: "não é de formulações que se trata, mas de uma nova orientação", p. 13. 
no homem, é irredutível às ciências da natureza; não evitou, por fim, "qualquer confusão com a fisiologia, a biologia ou qualquer outra ciência da natureza ou do homem enquanto natureza"5. Ao contrário. Continuou tratando o homem como homo natura, retomando uma expressão que Foucault utilizará ao falar da psicologia do século XIX, e acabou não definindo o psíquico como psíquico, em sua especificidade frente ao que no homem é natural.

Mas mesmo quando procurou ultrapassar a fisiologia para alcançar a consciência (quando, por exemplo, passou de uma perspectiva objetiva do corpo, para uma perspectiva subjetiva da consciência), não conseguiu se livrar dos modelos das ciências naturais. Mesmo quando a psicologia da introspecção, por exemplo, além das considerações sobre o funcionamento mecânico, biológico, físico e químico da percepção, procura explicar o funcionamento da consciência, estabelecendo seus procedimentos, as "formas do pensamento" e os "estados de consciência", ainda assim não apreende a especificidade do psíquico. Continua, como a medicina, a biologia ou a física, tratando os fatos, no caso os fatos psicológicos, como coisas; procura explicar o psíquico a partir de processos autônomos que teriam sido produzidos por causas impessoais. Aplica "aos fatos psicológicos a atitude que adoptamos para a explicação dos fatos objetivos em geral, quer dizer, o método da terceira pessoa"7. Ao invés de pensar que a especificidade do fato psicológico está justamente em implicar um "eu", a psicologia clássica procura abstrair esse "eu" a fim de encontrar procedimentos com causas impessoais, fatos em terceira pessoa: fatos autônomos, que ocorrem independentemente de um "eu".

Para Politzer, contudo, "subtrair ao fato psicológico o sujeito que o subentende corresponde a aniquilar a sua condição de psicológico"8. A originalidade da psicologia está precisamente na apreensão dos fatos que dependem de um "eu" e que não existem sem ele. Não um eu puro abstrato e impessoal, um centro funcional que opera funções abstratas, mas um eu singular e concreto, que em primeira pessoa está presente em todas as ações do sujeito.

E aqui começamos a nos aproximar do que Politzer vai chamar de psicologia concreta e que, aos seus olhos, é a única psicologia possível. A psicologia concreta é, em primeiro lugar, uma ciência que considera o fato psicológico como expressão de um "eu" singular; um fato cujo sentido só se compreende quando é pensado no interior da história individual de cada sujeito singular, como parte ou momento da vida psicológica como um todo.

5 POLITZER, Crítica II, p. 84.

6 Cf. POLITZER, Crítica II, p. 119.

7 POLIZTER, Crítica I, p. 58.

8 POLITZER, Crítica I, p. 66. Diz ainda Politzer: "Só a existência da primeira pessoa explica logicamente a necessidade de intercalar na série das ciências uma ciência psicológica; e se esta, tal como todas as outras, pode abandonar no decurso de sua evolução os motivos temporais que lhe deram origem, já não poderá certamente abandonar a relação dos factos à primeira pessoa, relação essa que lhe confere a originalidade de que ela necessita." (Crítica I, pp. 63-4) 
Para Politzer, as ciências da natureza não esgotam tudo o que se pode saber acerca dos homens. E se, com efeito, o termo "vida" designa um fato biológico, a vida dos homens ou a vida propriamente humana além de ser biológica é sobretudo uma "vida dramática"; uma viva vivida por um sujeito singular e concreto que, a cada dia, a partir de suas vivências psicológicas particulares, constrói sua história individual, o seu drama. Nesse contexto, o fato psicológico, em oposição ao fato biológico, consiste em qualquer gesto, ação ou comportamento que só tem sentido na medida em que é segmento do drama de uma vida humana, que é uma cena de uma longa encenação. E o papel da psicologia, mais especificamente do psicólogo, é o de compreender a inserção de cada gesto/ação/comportamento no interior de um drama individual, compreender de que modo uma ação particular se relaciona com demais ações de um sujeito e qual o seu sentido no interior da história de vida de cada um. Ao psicólogo, portanto, cabe uma tarefa interpretativa: encontrar o sentido de ações particulares, situando-as no interior de uma história individual.

Retomemos um exemplo dado por Politzer: "meu filho chora porque o vão deitar". O que a psicologia clássica teria a nos dizer acerca desse acontecimento? Trata-se de "secreção lacrimal consecutiva a uma representação que contraria uma tendência profunda" 10 . Ora, dirá Politzer, isso não é interpretar um acontecimento, mas somente descrevê-lo, e esse método em nada nos ajuda a compreender o seu sentido. Para Politzer, portanto, é preciso ultrapassar a mera observação e descrição e alcançar a interpretação. Essa é, pois, a tarefa de uma psicologia concreta: interpretar e expressar, por meio das palavras, isto é, por meio de uma narrativa, o sentido do comportamento humano. A narrativa é, pois, nesse contexto, a expressão de sentido de uma vida dramática, uma vida concreta e singular de um indivíduo singular ${ }^{11}$. A vida humana é um drama protagonizado por cada um de nós e ao psicólogo é dada a tarefa de construir a narrativa desse drama, expressar seu sentido por meio de palavras, quando isso não pode ser feito pelo próprio indivíduo que vive o drama.

Nesse sentido, é legítimo aproximarmos psicologia e literatura, afinal, como o escritor, em especial os romancistas, cabe aos homens construir suas próprias narrativas psicológicas: expressar, por meio de palavras, o sentido de suas ações no interior de um drama. E a literatura, assegura Politzer, deve mesmo ser utilizada pela psicologia já que problematizava a vida dramática muito antes que essa ciência ${ }^{12}$. Assim, mais do que as ciências naturais, é a literatura que fornece pistas acerca do funcionamento da vida psíquica; é ela, mais do que qualquer outro saber sobre o homem, que nos ajuda a compreender o sentido de nossas ações verdadeiramente humanas e que nos ajuda, portanto, a interpretá-las.

É o que faz Freud, por exemplo, quando se apropria de certo "esquema dramático" narrado por Sófocles em Édipo-Rei a fim de compreender o sentido de certos comportamentos

9 POLITZER, Crítica I, p. 27.

10 POLITZER, Crítica I, pp. 73-4.

11 Cf. POLITZER, Crítica I, p. 72.

12 Cf. POLITZER, Crítica I, Prefácio, p. 28. 
humanos. Com sua teoria do complexo Édipo, que afirma o desejo de matar o pai e esposar a mãe, Freud não procura explicar o funcionamento de certos processos ou estados mentais, nem tampouco mecanismos psicofisiológicos que estariam por trás de certas ações humanas, mas "a forma humana de uma encenação"13. Não procurava encontrar na tragédia grega nenhuma espécie de realismo psíquico, mas atitudes dramáticas: ações que possuem um sentido na medida em que fazem parte de uma história mais ampla; atos que fazem parte de uma encenação. Para Politzer isso é comportamento humano: conjunto de movimentos que possuem sentido no interior de uma história individual ${ }^{14}$.

É verdade que podemos argumentar, contra Politzer, que a teoria do complexo de Édipo elaborada por Freud acaba, mesmo que inadvertidamente, caindo nas abstrações da psicologia clássica. Ao se apropriar do drama de Édipo, Freud estendeu sua história a todos os homens, criando com um isso uma certa teoria em terceira pessoa que afirma que todo desejo humano é naturalmente incestuoso. Ou seja, independentemente do eu em questão, o desejo dos homens não tem barreiras. Por que não considerar isso como uma teoria geral sobre o homem? Ou ainda: uma lei natural do desejo humano?

Politzer reconhece que muitos leram Freud dessa maneira e insistiram que o central da psicanálise está em sua teoria da sexualidade, da libido ou do desejo ${ }^{15}$. Para o autor da Critique, contudo, o mais interessante da psicanálise não está naquilo que dá continuidade à psicologia da época, mas naquilo que rompe com ela. Nesse sentido, garante Politzer: Freud não é só "evolução da psicologia clássica, é revolução; mostra seu fim". ${ }^{16}$

Assim, mesmo que em Freud seja possível encontrar resquícios de uma psicologia naturalista, que tende a pensar o homem como ser natural, como um ser que possui certo modo de funcionamento independentemente de um eu singularmente situado, para Politzer, a inovação da psicanálise está naquilo em que a aproxima de uma psicologia concreta. Aos olhos de Politzer, o mérito da psicanálise está em ser uma ciência construída a posteriori a partir de deduções provenientes da experiência, que nos permite compreender certas ações e comportamentos humanos, situando-os no interior da história individual ou da vida dramática de cada um. Esse é, pois, o aspecto mais importante da teoria freudiana do complexo de Édipo. O esquema dramático da tragédia de Édipo, generalizado a todos os homens, permite ao psicanalista interpretar e dar sentido a uma série de ações (sonhos, atos falhos, sintomas etc) de cada um de seus pacientes. Serve "para a análise e a reconstituição do drama humano"17.

Para Politzer, portanto, a psicologia concreta tem, por definição, a incumbência de promover interpretações, de compreender e dar sentido às ações dos homens situando-as no

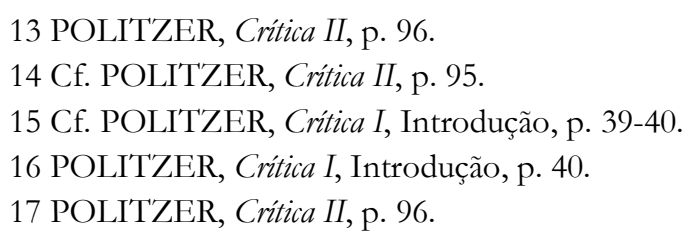


interior de suas histórias individuais. Retomando então certos comportamentos de uma criança, Politzer procura deixar clara a distância que separa a psicologia clássica e a psicologia concreta. E é nesse contexto que a psicanálise pode, em parte, ser considerada uma psicologia desse tipo. Vejamos então o exemplo.

Uma criança perde o gatinho de estimação e passa a dizer que ela mesma é o gato; começa a andar de quatro e se recusa a comer à mesa. Para a psicologia clássica, garante Politzer, esse fenômeno é explicado a partir da noção de imitação: "passagem imediata de uma percepção, normalmente visual, a um movimento que reproduz a causa da percepção"18. Logo se vê que o sentido do comportamento não está em questão; limita-se a dar uma explicação meramente formal dos atos mentais implicados na ação, "limita-se ao mecanismo geral deste", confirma o autor ${ }^{19}$. Abstrai-se que o comportamento foi realizado por um "eu" particular e que o conteúdo, e não a forma do ato, é o verdadeiro elemento psicológico que deve ser compreendido. Por outro lado, se a psicologia clássica, por meio da noção de imitação não consegue compreender o significado do comportamento infantil, a psicanálise, enquanto psicologia concreta, torna possível interpretar o conteúdo desse comportamento por meio da noção de identificação. Diante da perda do objeto amado, o gato, a criança, a fim de minimizar a dor, e como mecanismo de defesa e de luto, procura se identificar com o objeto perdido e ser como ele. Essa, sim, é uma interpretação que nos ajuda a compreender o sentido do comportamento infantil e que aponta para a verdadeira tarefa da psicologia.

\section{II - Foucault e a crítica ao humanismo}

Muita coisa aconteceu na história da psicologia desde 1928, quando Politzer exalta a psicologia concreta como sendo a verdadeira psicologia. Nesse sentido, valeria a pena resgatar a maneira como, quase trinta anos depois da publicação da Critique, Foucault nos mostra o desenrolar dessa história e propõe uma crítica da psicologia que nos parece muito mais avassaladora do que aquela de Politzer.

Como se sabe, Foucault se interessara pela psicologia desde o início de seu percurso intelectual. Graças às notas biográficas indicadas pelos editores no volume I dos Dits et écrits, é possível traçar com clareza seu intenso envolvimento com essa ciência, desde sua entrada na École normale supérieure (ENS), em 1946, até sua ida para à Suécia, em 1955. Em 1946, Foucault é aceito na ENS; em 1947, segue os cursos de Merleau-Ponty nessa mesma instituição, que determinarão seu primeiro projeto de tese sobre o nascimento da psicologia nos pós-cartesianos; em 1949 é aceito no curso de psicologia da Sorbonne, onde Merleau-Ponty continua dando seus cursos; em 1951 recebe a agrégation de filosofia, passa a ministrar curso sobre psicologia na ENS, a trabalhar

18 POLITZER, Crítica II, p. 92.

19 POLITZER, Crítica II, p. 92. 
como psicólogo num laboratório de psicologia experimental, assim como a redigir a tese sobre o nascimento da psicologia; em 1952 recebe o diploma em psicopatologia, começa a lecionar psicologia na Universidade de Lille, e, provavelmente, começa a escrever um artigo sobre Binswanger; em 1953, recebe o diploma de psicologia experimental, apresenta um pequeno ensaio sobre a psicopatologia materialista inspirada em Pavlov ao grupo de alunos comunistas reunidos em torno de Althusser, escreve artigo sobre a constituição da psicologia científica, dá curso sobre Freud na ENS, segue os seminários de Lacan no Hospital Saint-Anne, traduz vários casos e artigos de Binswanger, assim como visita o autor na Suíça; em 1954 é publicado pela P.U.F. seu primeiro livro, Maladie mentale et personalité, encomendado por Althusser, e a introdução e a tradução do livro Traum und Existenz de Binswanger.

Os escritos de Foucault da década de 1950 refletem, com efeito, uma inserção bastante diversificada no campo da psicologia, mas nos permitem sobretudo traçar o início de um percurso intelectual que dará origem à sua filosofia. Em linhas gerais, podemos dizer que, na década de 50 , a relação de Foucault com a psicologia divide-se basicamente em dois momentos diferentes; um fenomenológico, outro marxista. No primeiro momento (o da introdução ao texto de Binswanger, escrito provavelmente em 1952), Foucault mostra-se crítico, por motivos diferentes, como veremos, tanto em relação à psicologia clássica quanto em relação à psicanálise freudiana, e toma partido da fenomenologia, em especial, daquela colocada em prática pela psiquiatria existencial. No segundo momento, parece dar uma virada marxista e passa a criticar tanto a psicologia clássica e a psicanálise, como a perspectiva existencial em psicologia. É o que mostra o livro de 54, Maladie mentale et personalité que, depois de apresentar uma breve história da psicologia, passando pela psicologia evolucionista, pela psicanálise e pela psiquiatria existencial, discute, na segunda parte, as origens sociais das doenças, ou, como diz Foucault, suas condições exteriores e objetivas.

Na primeira redação que fizera da introdução ao segundo volume da Histoire de la sexualité, L'usage des plaisirs, e que fora publicada somente na edição americana do livro, em 1984, Foucault faz uma espécie de retrospectiva de sua obra e retoma essa mudança de perspectiva do início de seu percurso intelectual. Afirma que desde seus primeiros trabalhos interessava-se por uma investigação histórica da experiência, que as primeiras tentativas nesse sentido se inscreveram no domínio da fenomenologia e, depois, no do marxismo. Por fim, reconhece ainda que a perspectiva marxista também mostrou-se insatisfatória e que teria sido preciso o desenvolvimento de um outro método, o arqueológico 20.

Não nos cabe aqui retomar todo esse caminho que vai do Foucault fenomenólogo, passando pelo Foucault marxista até chegar ao arqueólogo. Por ora, interessa retomar a posição fenomenológica inicial de Foucault a fim de mostrar que desde o início o filósofo se distancia da

20 Cf. FOUCAULT, "Préface à l'Histoire de la sexualité”, p. 1397. 
psicologia concreta de Politzer e de seus elogios à psicanálise ${ }^{21}$. Deixemos, então, para outro momento a discussão sobre a virada marxista de Foucault, seu subsequente deslocamento que vai desembocar na arqueologia ou sobre outro possível confronto que poderíamos estabelecer entre Politzer e Foucault, levando em conta não tanto a Critique des fondements de la psychologie, mas os escritos posteriores de Politzer que são ainda mais ácidos com a psicanálise e que talvez sejam mais afins à leitura que Foucault fizera, na década de 50, da psicologia clássica e da psicanálise.

A primeira parte do livro Maladie mentale et personalité consiste numa breve história da psicologia. Essa parte é mantida praticamente igual na segunda versão da obra publicada em 1962 e rebatizada como Maladie mentale et psychologie. Nela, Foucault traça uma espécie de progresso no interior da história da psicologia e sugere que, de meados do século XIX a meados do século XX, o que se vê são sucessivas tentativas de superar os prejuízos da psicologia clássica. Todas elas compartilham a tese de que a doença mental não pode ser pensada exatamente nos mesmos termos que as doenças do corpo; era preciso determinar a especificidade das doenças psicológicas frente às doenças do corpo e estar atento às "dimensões psicológicas da doença", título que recebe essa primeira parte do livro. E, em artigo de 1957, intitulado precisamente "La psychologie de 1850 à 1950", Foucault esclarece o que entende por psicologia clássica: aquela que se pretendia conhecimento positivo e que repousava sobre dois postulados filosóficos: "que a verdade do homem limita-se ao seu ser natural e que o caminho de todo conhecimento científico deve passar pela determinação das relações quantitativas, a construção de hipóteses e a verificação experimental" 22. Ou seja, assim como Politzer, Foucault reconhece que o destino da psicologia contemporânea fora o de superar a psicologia clássica do século XIX, que pensava o homem exclusivamente como homo natura e que procurava conhecê-lo a partir dos mesmos métodos empregados nas ciências naturais.

Dentre as correntes analisadas por Foucault, o modelo evolutivo é o único que não se desembaraçou por completo do naturalismo e das abstrações da psicologia clássica. Procura compreender a especificidade da doença mental frente às doenças do corpo, pensa a vida psicológica de maneira mais dinâmica e complexa, fala em fases, história e orientação das doenças; entretanto, não dá conta de compreender o aparecimento da doença e o seu significado no interior da história do doente. Confirma Foucault retomando a tópica politzeriana da abstração:

21 O presente artigo, portanto, vai na contramão daquele de Osmyr Faria Gabbi Junior "Foucault e a psicanálise na década de 1950”. Enquanto Gabbi Junior chama atenção para as convergências existentes entre as críticas politzerianas à psicologia e aquelas que encontramos nos textos da década de 50 de Foucault, aceno, aqui, para as divergências entre os autores. Isso porque, a meu ver, a distância que separa Politzer e Foucault indica a posição filosófica inicial de onde parte Foucault: a fenomenologia. Mostra, portanto, que inicialmente o filósofo tende a ler a psicologia mais em seu vínculo com a fenomenologia do que com o marxismo. A virada marxista, como veremos, virá em seguida. Não tanto, porém, pela influência de Politzer e de sua psicologia concreta, mas pela influência de Althusser e pela aposta numa "psicologia do conflito" inspirada em Pavlov.

22 FOUCAULT, “La psycologie de 1850 à 1950”, p. 148. 
(...) a noção abstrata de regressão não pode dar conta do fato de que uma pessoa esteja doente, e esteja doente neste momento, desta doença, que suas obsessões tenham determinado tema, que seu delírio comporte tais reivindicações, ou que suas alucinações se extasiem no universo de certas formas visuais. ${ }^{23}$

Ou seja, apesar do modelo evolucionista ter dado um passo à frente em relação ao modelo experimental da psicologia do século XIX ao pensar a doença em termos de história e de processos psicológicos, ele não foi capaz de situar a história da doença no interior da história do doente. Com os termos de Foucault: pensou a orientação da doença em termos de força, mas não em termos de significação ${ }^{24}$.

Pensar o sentido da doença no interior da história pessoal do doente fora então a tarefa que a psicanálise herdara da tradição. Aqui, então, Foucault parece estar, mais uma vez, de acordo com Politzer, ao reconhecer a importância da psicanálise no interior da história da psicologia. Vimos acima que, segundo Politzer, a psicanálise provoca uma revolução na psicologia. Também para Foucault, foi a psicanálise quem verdadeiramente chamou atenção para a especificidade do objeto da psicologia: não os processos naturais, gerais e abstratos que compõem a vida psíquica, mas o sentido e o significado desses processos, a maneira como singularmente os sujeitos dão sentido às suas vivências e experiências. Nesse contexto, Foucault parece levar à risca os ensinamentos de Politzer que, em 1928, afirmava: "a psicanálise procura sempre a compreensão dos fatos psicológicos em função do sujeito” 25 .

De acordo com Foucault, é somente a partir da psicanálise que se estabelece que o objeto da psicologia não é mais o homo natura, mas o homo psychologicus. E o reconhecimento do caráter inaugural da psicanálise frente à psicologia clássica é evidente a Foucault desde seu primeiro escrito, a introdução ao livro de Binswanger, Traum und Existen₹: Nesse texto, ao lado de Husserl, Freud aparece como alguém atento ao grande problema suscitado pelo nascimento das ciências humanas: o da compreensão do sentido e da significação. É só com a psicanálise, por exemplo, que os sonhos ganham estatuto psicológico; deixam de ser considerados resquícios caóticos de estímulos sensíveis passados e passam a ter um sentido no interior da história afetiva do sujeito. São como os sintomas: apresentam um sentido latente que deve ser perscrutado pelo analista; este, portanto, não está somente atento aos modos de aparição da doença, à evolução física dos sintomas, mas quer sobretudo compreender o sentido psicológico de sua orientação.

23 FOUCAULT, Doença mental e psicologia, p. 37; FOUCAULT, Maladie mentale et personalité, p. 34; (as citações em português referentes à primeira parte do livro Doença mental e psicologia, de 1962, por serem iguais ao da primeira versão do livro, de 1954, serão seguidas pela paginação da edição francesa dessa versão visto que ela não foi traduzida para o português).

24 FOUCAULT, “La psychologie de 1850 a 1950”, p. 153.

25 POLITZER, Crítica I, p. 61 
Desde seus primeiros escritos pode-se dizer que Foucault encara a psicanálise como uma psicologia concreta. Reconhece que seu esforço maior é superar as abstrações das teorias psicológicas anteriores e mostrar que o comportamento humano, suas ações, seus sintomas, seus sonhos etc. têm um sentido no interior da história do sujeito. É o que Foucault deixa claro na seguinte passagem:

A psicologia da evolução, que descreve os sintomas como condutas arcaicas, deve, então, ser completada por uma psicologia da gênese que descreve, numa história, o sentido atual destas regressões. É preciso encontrar um estilo de coerência psicológica que autorize a compreensão dos fenômenos mórbidos sem tomar como modelo de referência estágios descritos à maneira de fases biológicas. É necessário encontrar o centro das significações psicológicas a partir do qual, historicamente, ordenam-se as condutas mórbidas. ${ }^{26}$

Mas, se, por um lado, Foucault parece endossar, desde o início da década de 50, as críticas de Politzer ao naturalismo da psicologia clássica e o caráter revolucionário da psicanálise enquanto uma psicologia do concreto, por outro lado, já nesse período também aponta ressalvas aos elogios que a Critique teceu à ciência de Freud. É verdade que também Politzer é um crítico da psicanálise; e isso já na Critique. Nesse livro, contudo, a reprovação politzeriana da psicanálise se refere somente aos resquícios da psicologia clássica que ainda se encontravam nela, como as descrições gerais e abstratas que Freud propõe no capítulo VII de Die Traumdentung, sobre os processos oníricos ${ }^{27}$. Foucault também reconhece que Freud, em muitos momentos, perde de vista o bomo psychologicus, recoloca no centro da cena o homo natura e apresenta hipóteses abstratas e míticas sobre o funcionamento psíquico. Aos olhos de Foucault, no entanto, essa não é a única insuficiência da psicanálise. E desde o texto sobre Binswanger, chama atenção para uma deficiência que, ao que tudo indica, é ainda mais comprometedora do que aquela já apontada por Politzer.

No início da década de 50, sob impacto da carta de Heidegger a Jean-Beaufret sobre o humanismo, de 1948, assim como dos ensinamentos de Jean Hyppolite que procurava ler a fenomenologia hegeliana à luz de Heidegger, mais como ontologia do que como um humanismo, Foucault condena a psicanálise por manter-se presa a uma perspectiva demasiadamente antropológica e humanista do homem ${ }^{28}$. Ela psicologiza demais o sentido; é incapaz de perceber que o significado de nossas ações ultrapassa nossa história individual e se liga, antes de mais nada, à nossa condição existencial primordial. Em sua breve história da psicologia contemporânea,

26 FOUCAULT, Doença mental e psicologia, p. 52; Maladie mentale et personalité, p. 51.

27 Cf. POLITZER, Crítica I, cap. III, "A estrutura teórica da psicanálise e as sobrevivências da abstração".

28 Sobre as leituras de Hyppolite sobre Hegel, Heidegger e Freud, que influenciaram sobremaneira Foucault, cf. HYPOLLITE, Figures de la pensée philosophique. 
Foucault, então, justifica a passagem da psicanálise à psiquiatria existencial: “A análise da evolução situava a doença como uma virtualidade; a história individual permite encará-la como um fato de devir psicológico. Mas é preciso agora compreendê-la na sua necessidade existencial" 29 .

É no texto sobre Binswanger que Foucault desenvolve com maior acuidade a necessidade de se passar de Freud a Binswanger. O mérito da psiquiatria existencial estaria no fato de conciliar a psicologia concreta da psicanálise com uma ontologia. Com isso, ela tem um alcance maior no que diz respeito à compreensão do sentido de nossas ações. Está atenta à história individual dos doentes e procura compreender o significado da doença no interior do drama de cada um, porém, além do sentido psicológico do comportamento humano, busca também compreender seu sentido existencial. Com os termos de Foucault: a psiquiatria existencial supera o humanismo e antropologismo da psicanálise; não se restringe a pensar o significado eventual e particular das ações humanas (antropologismo e humanismo), mas vê nelas a expressão de certos modos universais, e necessários, de ser e de existir (ontologia).

Mas, se no texto de Foucault sobre Binswanger, a fenomenologia é elogiada por superar o humanismo da psicanálise por meio de uma ontologia, num texto logo posterior, Maladie mentale et pernsonalité, publicado no mesmo ano de 1954, ela será acusada de subjetivismo. E agora, ao lado da psicanálise, será criticada por considerar a experiência de um ponto de vista exclusivamente subjetivo. É verdade que a psiquiatria existencial não se restringe a uma perspectiva psicológica do sujeito, mas mesmo a perspectiva transcendental da existência e do ser será vista, a partir de então, como uma perspectiva subjetivista. Ela leva em conta somente as condições subjetivas do homem como condições necessárias e suficientes da experiência.

É, então, precisamente esse subjetivismo que Foucault procura ultrapassar na segunda parte do livro de 1954, dando o tom radical de sua crítica à psicologia. Todas as vertentes da psicologia contemporânea, garante Foucault, incluindo aí tanto a psicanálise, em sua perspectiva concreta, quanto a psiquiatria existencial, com sua perspectiva transcendental, mostraram as diferentes formas de aparição das doenças mentais, contudo, nenhuma delas foi capaz de demonstrar suas condições reais de aparição ${ }^{30}$. Estavam muito presas às condições subjetivas da doença e não atentaram para suas condições objetivas. Arremata, então, Foucault em Maladie mentale et personalité:

(...) pode-se dizer que as dimensões psicológicas da doença não podem, sem nenhum sofisma, serem encaradas como autônomas. Certamente, podemos situar a doença mental em relação à evolução humana, em relação à história psicológica e individual, em relação às formas de existência. Mas não podemos confundir esses diversos aspectos da doença com suas origens reais, caso não queiramos apelar a explicações míticas, como a evolução das estruturas psicológicas, ou a teoria dos

29 FOUCAULT, Doença mental e psicologia, p. 53; Maladie mentale et personalité, p. 52.

30 FOUCAULT, Doença mental e psicologia, p. 71; Maladie mentale et personalité, p. 71. 
instintos, ou uma antropologia existencial. Na realidade, é na história somente que podemos encontrar as condições de possibilidade das estruturas psicológicas (..... ${ }^{31}$

Era preciso, pois, uma virada marxista. Foucault conclui o livro com um capítulo sobre Pavlov para mostrar qual seria a verdadeira tarefa da psicologia: a psicologia deve investigar a maneira como os indivíduos reagem aos conflitos do meio e ajudá-los a não se alienarem nessa interação. Diz Foucault nas linhas finais:

(...) a verdadeira psicologia deve se livrar dessas abstrações que obscurecem a verdade da doença e alienam a realidade do doente; pois, quando se trata do homem, a abstração não é simplesmente um erro intelectual; a verdadeira psicologia deve se desembaraçar desse psicologismo, se é verdade que, como toda ciência do homem, ela deve ter por objetivo desaliená-lo ${ }^{32}$.

Como atesta a segunda versão do livro de 54, porém, publicada em 1962 e rebatizada como Maladie mentale et psychologie, a virada marxista ou objetvista da psicologia via Pavlov não durou muito tempo. Na nova edição da obra, a segunda parte do livro é modificada e o capítulo sobre Pavlov, excluído. No seu lugar o que se vê é um resumo de Histoire de la folie, publicado um ano antes, e um esboço de uma análise arqueológica acerca do nascimento da Psicologia. A crítica da psicologia, em Foucault, atinge, enfim, sua resolução e desemboca na arqueologia. Uma arqueologia que coloca como tarefa tanto da psicologia, quanto da filosofia, pensar o homem, não só na história, mas completamente tramado por ela, pensar não só a história das formas da experiência, mas "a historicidade mesma das formas da experiência" 33 .

Não nos cabe aqui desenvolver as particularidades do método arqueológico, nem tampouco suas diferenças frente a uma psicologia do comportamento nos moldes de uma análise objetiva dos condicionantes materiais. O importante é notar que desde a versão de 54 do livro Maladie Mentale et personalité, Foucault critica a pretensão de uma psicologia aliada a uma filosofia do sujeito que pensa a experiência do homem a partir de condições exclusivamente subjetivas, sejam elas psicológicas ou existenciais e ontológicas.

Assim, se inicialmente dissemos que a crítica de Foucault à psicologia, desde seus primeiros escritos da década de 50, parece ser mais radical do que aquela de Polizer, ao menos daquela desenvolvida na Critique des fondements de la psychologie, é porque ele rejeita não só o caráter humanista e antropológico da psicanálise, mas também e sobretudo o caráter subjetivista tanto das psicologias concretas quanto das psicologias de cunho transcendental ou existencial.

31 FOUCAULT, Maladie mentale et personalité, p. 90.

32 FOUCAULT, Maladie mentale et personalité, p. 110.

33 FOUCAULT, "Préface à la 'Histoire de la sexualité", p. 1398. 
O que se vê, então, logo nos primeiros escritos de Foucault é uma posição anti-humanista e antissubjetivista que anuncia as teses que causarão alvoroço quando, na década de 60 , o filósofo afirmar com veemência a morte do homem e a morte do sujeito. Não me parece descabido dizer, portanto, que, já aos olhos do jovem Foucault, a psicologia concreta de Politzer não passa de mais uma reflexão sobre o homem e de uma "filosofia do sujeito" que "vê no sujeito a fundação de todo conhecimento e o princípio de toda significação" 34 . Afinal, pensar o homem como autor de seu próprio drama não seria justamente pensar o homem como medida de todas as coisas e dar centralidade ao sujeito no que diz respeito à construção do sentido de nossas experiências, nossos atos e nossos comportamentos? É precisamente a recusa de uma posição soberana do homem e do sujeito que marca a crítica foucaultiana à psicologia e que, a meu ver, a torna mais radical do que aquela tecida em 1928 por Politzer em Critique des fondements de la psychologie.

\section{CONCRETE PSYCHOLOGY AND HUMANISM: POLITZER'S CRITICAL FOUCAULT?}

Abstract: In the present article we intend to confront Foucault's critique of psychology and psychoanalysis in his texts written during the 1950s, with Georges Politzer's criticism included in his famous Critique of the Fundamentals of Psychology, published in 1928. Despite some points of convergence, Foucault's critique is, from the beginning, more radical than that of Politzer and reaches even the concrete psychology proposed by him.

Keywords: psychology - psychoanalysis - criticism - Foucault - Politzer

\section{Referências bibliográficas:}

BIANCO, Giuseppe. “Apresentação”. In: POLITZER, G. “O fim da psicanálise”. Tradução. G. C. O. Silva. In: Lacuna: uma revista de psicanálise, São Paulo, n³, p. 14, 2017. Disponível em: $<$ https://revistalacuna.com/2017/04/28/n3-14/

- (org) Georges Politzer, le concret et sa signification. Psychologie, philosophie et politique. Paris: Hermann Éditeurs, 2016.

FOUCAULT, Michel. Maladie Mentale et personalité. Paris: P.U.F., 1954.

- "Verdade e subjetividade". Tradução António Fernando Cascais. In: Revista de Comunicação e Linguagens, n’ 19. Lisboa: Edições Cosmos, 1993.

- Maladie Mentale et psychologie. (Doença mental e psicologia. Tradução de Lilian Rose Shalders. Rio de Janeiro: Tempo Brasileiro, 2000).

34 FOUCAULT, “Verdade e subjetividade”, p. 204. 
. "Préface à l'Histoire de la sexualité", in Dits et écrits, vol II. Paris: Gallimard, 2001.

. "La psychologie de 1850 a 1950", in Dits et éctris, vol I. Paris: Gallimard, 2001.

HYPPOLITE, Jean. Figures de la pensée philosophique. Paris: P.U.F., 1971.

JUNIOR, Osmyr Faria Gabbi. "Foucault e a psicanálise na década de 1950". In SIMANKE, R.T. e al. (orgs.). Filosofia da Psicanálise: autores, diálogos, problemas. São Carlos: EdUFSCar, 2010.

POLITZER, Georges. Critique des fondements de la psychologie. (Crítica dos fundamentos da psicologia, vol. I e II. Tradução de Conceição Jardim e Eduardo Lúcio Nogueira. Portugal: Editora Presença e Brasil: Martins Fontes, 1975). 